\title{
El cambio climático y la pandemia de COVID-19
}

\section{Climate change and the COVID-19 pandemic}

\author{
María del Carmen Lacy-Niebla \\ Instituto Nacional de Cardiología Ignacio Chávez, Ciudad de México, México
}

El cambio climático es el cambio de clima que se atribuye directa o indirectamente a la actividad humana que altera la composición de la atmósfera del planeta y que se suma a la variabilidad natural del clima que ocurre durante periodos de tiempo comparables. El cambio climático ha existido desde los inicios del planeta, ya sea en forma súbita o gradual, y se ha derivado de varios fenómenos, como las variaciones de radiación solar, periodos de actividad volcánica intensa, impactos de meteoritos, cambios en la órbita del planeta y otros, pero el impacto de la actividad humana también ocasiona cambio climático en forma intensa al producir emisiones por los vehículos automotores, la actividad industrial, la deforestación de nuestros bosques y selvas y por la introducción de sustancias contaminantes a la atmósfera, biósfera e hidrósfera. El cambio climático avanza mucho más rápido que todas las acciones que hacemos para controlarlo y exponemos al planeta a daños irreversibles.

Durante siglos, los seres humanos hemos disfrutado de lo que la naturaleza nos ofrece y si bien en general valoramos los beneficios de un medio ambiente sano, hay sectores que luchan en contra de las medidas conservadoras de este ambiente saludable, y generalmente involucran intereses políticos y económicos. Debe existir un equilibrio que favorezca la vida productiva y saludable con refugio, agricultura, alimentación, diversión, cultura, reproducción, creatividad y control adecuado de los desperdicios orgánicos e inorgánicos.
El crecimiento poblacional y económico demanda recursos y energía que generan calentamiento global y la pérdida de sistemas ecológicos por su irracional e ilimitado uso. Los medios biológicos y físicos se convierten entonces en limitantes para el crecimiento adecuado de las poblaciones. Si les es permitido, todas las especies tienden a crecer en forma exponencial y los límites están dados por los recursos que se requieren para ello.

El crecimiento poblacional lleva a limitar el hábitat de los animales, acorrala a la mayoría de las especies, pero principalmente a los roedores, que son los reservorios de grandes enfermedades pandémicas. El desarrollo económico que domina la actividad humana suele ignorar las leyes de la naturaleza para que esta sea adecuada para la vida, rompe su equilibrio natural y nos lleva a un desarrollo no sustentable.

El cambio climático daña gravemente la salud tanto de los seres humanos como del resto de las especies animales que habitan el planeta y de las plantas también. El impacto en la salud se ha acelerado en los últimos años al sufrir con mayor frecuencia golpes de calor, deshidratación, alteraciones en la salud mental, en la salud neurológica, cardiovascular y renal, con mayor frecuencia y gravedad de enfermedades virales respiratorias y sistémicas. La mayor amenaza a la salud y al equilibrio social y cultural es la creencia de que el calentamiento global y el cambio climático no son reales. Los expertos calculan que el calentamiento llegue a $1.5{ }^{\circ} \mathrm{C}$ más entre el año 2030 y el 2050 si

\section{Correspondencia:}

María del Carmen Lacy-Niebla,

E-mail: maricarlacy@yahoo.com
Fecha de recepción: 13-04-2021

Fecha de recepción: 21-04-2021

DOI: 10.24875/ACM.M21000076
Disponible en internet: 02-07-2021 Arch Cardiol Mex. 2021;91(3):269-271 www.archivoscardiologia.com CC BY-NC-ND (http://creativecommons.org/licenses/by-nc-nd/4.0/). 
continúa aumentando al ritmo que lleva actualmente. El impacto en la biodiversidad y en los ecosistemas, entre ellos la pérdida de las especies, será mayor a mayor temperatura global se alcance. Estamos alterando la temperatura de los mares y los niveles de acidez del agua, lo que afecta a miles de especies marinas y su supervivencia. Las aves han cambiado sus procesos de migración y los mamíferos terrestres también están amenazados. Los grandes incendios que han sido provocados por el aumento en la temperatura y la disminución de las lluvias cada vez son más difíciles de combatir y devastan grandes áreas de bosques y selvas que son primordiales en las estrategias para no superar los $1.5^{\circ} \mathrm{C}$ que tanto tememos.

El progresivo deterioro de los ecosistemas debido al modelo de producción de alimentos e insumos tomado de la naturaleza dio origen a esta pandemia que estamos sufriendo provocada por el coronavirus 2 del síndrome respiratorio agudo grave (SARS-CoV-2) y también las últimas pandemias en el mundo.

La pandemia ha sido otro de los grandes momentos de autodestrucción que se ha dado en la especie humana. La forma en que el virus irrumpió en nuestra vida es una dislocación del medio ambiente propiciada por nuestra búsqueda de un siempre elusivo desarrollo.

El tipo de desarrollo que hemos decidido adoptar nos ha llevado a estándares de vida aparentemente atractivos, pero para nada sustentables. Los estilos de vida están enfocados hacia cosas materiales. No debemos seguir deteriorando los ecosistemas. Tenemos la obligación de conservar el planeta Tierra.

La pérdida del contacto con la naturaleza dio paso a la enfermedad por coronavirus 2019 (COVID-19) por una forma de vida que dañó profundamente la biodiversidad y el medio ambiente. Se supone que somos seres inteligentes, pero no lo hemos estado haciendo bien por haber perdido la relación que tenía el ser humano con la naturaleza.

La demanda de alimentos, de energía, de modernidad, nos ha llevado a la destrucción del medio ambiente.

Hemos degradado extensas poblaciones forestales y selváticas para cultivar alimentos y criar ganado. Cada cosa que consumimos tiene un impacto en la naturaleza. La deforestación, el desarrollo agrícola y el cambio climático están causando incremento en enfermedades transmitidas por vectores. La pandemia de COVID-19 es el resultado de la perturbación ocasionada por la actividad humana sobre la naturaleza. En un gran número de las enfermedades infecciosas, el patógeno ha vivido en otra especie previa a la humana. Dichas especies han sido parte integral de los ecosistemas por cientos de años, pero cuando el ser humano interviene en su transformación, al destruir algún componente se genera un desequilibrio importante. Las organizaciones mundiales encargadas de la salud han pedido reiteradamente que se suspenda la venta de animales salvajes vivos en los diferentes mercados de alimentos alrededor del mundo. El origen de más del $75 \%$ de las enfermedades infecciosas emergentes en los humanos son estos animales. El equipo de investigación que recientemente visitó la ciudad y el mercado de alimentos de Hunan en Wuhan, China, señaló que el SARS-CoV-2 seguramente fue transmitido de los murciélagos a los humanos con otro animal intermediario. La cadena que existe entre enjaular a los animales salvajes en los mercados de alimentos, su sacrificio posterior con la contaminación que esto conlleva de las áreas de venta de alimentos, constituye un gran riesgo para la transmisión de diversos microorganismos patógenos tanto para los compradores como para quienes atienden los mercados, y de ahí su rápida propagación al resto de la población.

Otro factor es la amenaza a la diversidad biológica de especies invasoras, lo que genera problemas de pérdida de fauna o flora local por la agresividad de su explotación sin tener controles biológicos adecuados.

Cuando se invaden ecosistemas sin el manejo sustentable de los mares, praderas, bosques y selvas, así como de manglares, ríos y lagos, es cuando hay brotes infecciosos, porque se genera el desequilibrio entre los depredadores y sus presas.

Los humanos tenemos que aprender a darle el verdadero valor a las formas de uso sustentable. Es nuestra obligación reducir la pérdida de los ecosistemas y el uso sabio de los recursos naturales.

Estamos ante una emergencia mundial sin precedentes. El cambio climático y las acciones que el ser humano realiza en contra del equilibrio en la naturaleza son una grave amenaza para el planeta y, sin embargo, parece ser que la pandemia de COVID-19 ha hecho que olvidemos la estrecha relación que existe entre ambas situaciones. En los últimos meses hemos reaccionado más a la pandemia que a esta emergencia climática, sin saber de la estrecha relación que ambas tienen. No debemos olvidar una amenaza para combatir a la otra, van de la mano y están íntimamente unidas.

La pérdida de biodiversidad actúa como catalizador para la expansión del virus y enfermedades infecciosas.

Si disminuimos esta biodiversidad y destruimos ecosistemas, facilitamos que dichos virus pasen al ser humano. Hemos olvidado que la biodiversidad funciona 
como un escudo protector, ya que muchas especies actúan como huéspedes de virus y patógenos que tal vez ni siquiera hemos detectado el día de hoy. Para evitar nuevas pandemias debemos proteger la biodiversidad y fomentar ecosistemas sostenibles. No hay tiempo que perder. Esta pandemia nos ha enseñado que la salud del planeta está realmente en nuestras manos. Los modelos de producción y consumo desmedido necesitan desaparecer para permitir un sistema que garantice el uso sostenible de los recursos para las siguientes generaciones.

Estamos obligados a reducir las emisiones de los vehículos automotores, de la industria y de las centrales eléctricas. Tenemos que aprender a no desperdiciar alimentos, ya que diariamente se tira como basura cerca del $35 \%$ de estos. Debemos buscar una ruta de desarrollo sustentable. Si algo hemos aprendido con la pandemia actual, es la necesidad de gestionar la sustentabilidad de los recursos naturales. Durante años hemos cambiado las leyes de la naturaleza, hemos deforestado, acelerado la migración de las poblaciones del campo a las grandes urbes, hemos contaminado mares, cielos y tierra, y utilizamos recursos no renovables. Al consumir especies salvajes, principalmente de roedores, hemos cambiado a los patógenos de huésped, y esos huéspedes a menudo somos nosotros, los seres humanos.

Es por ello que debemos apostar por un sistema de vida sostenible, invertir en energías renovables, reducir la contaminación, el calentamiento global y el cambio climático.

La educación de las nuevas generaciones es de vital importancia. De no actuar de forma inmediata, el planeta sufrirá cambios irreversibles, la humanidad padecerá cada días más sed y hambre y enfermedades emergentes que lleven a pandemias como la que estamos viviendo en este momento, y como consecuencia, el mundo se convertirá en uno cada vez más violento y ansioso, con migraciones masivas y graves problemas sociales.

La solución está en las acciones que tome de forma inmediata la humanidad, sin olvidar el poder de la educación para lograr conseguir primero un cambio individual y luego el cambio global. Este es un desafío mundial que requiere de acciones coordinadas, pero cada uno de nosotros como individuos debemos ejercer con responsabilidad nuestro papel en el planeta Tierra. 